\title{
Health education and peer leaders' role in improving low vaccination coverage in Akre district, Kurdistan region, Iraq
}

M.A. Abdul Rahman, ${ }^{7}$ S.A. Al-Dabbagh ${ }^{7}$ and Q.S. Al-Habeeb ${ }^{1}$

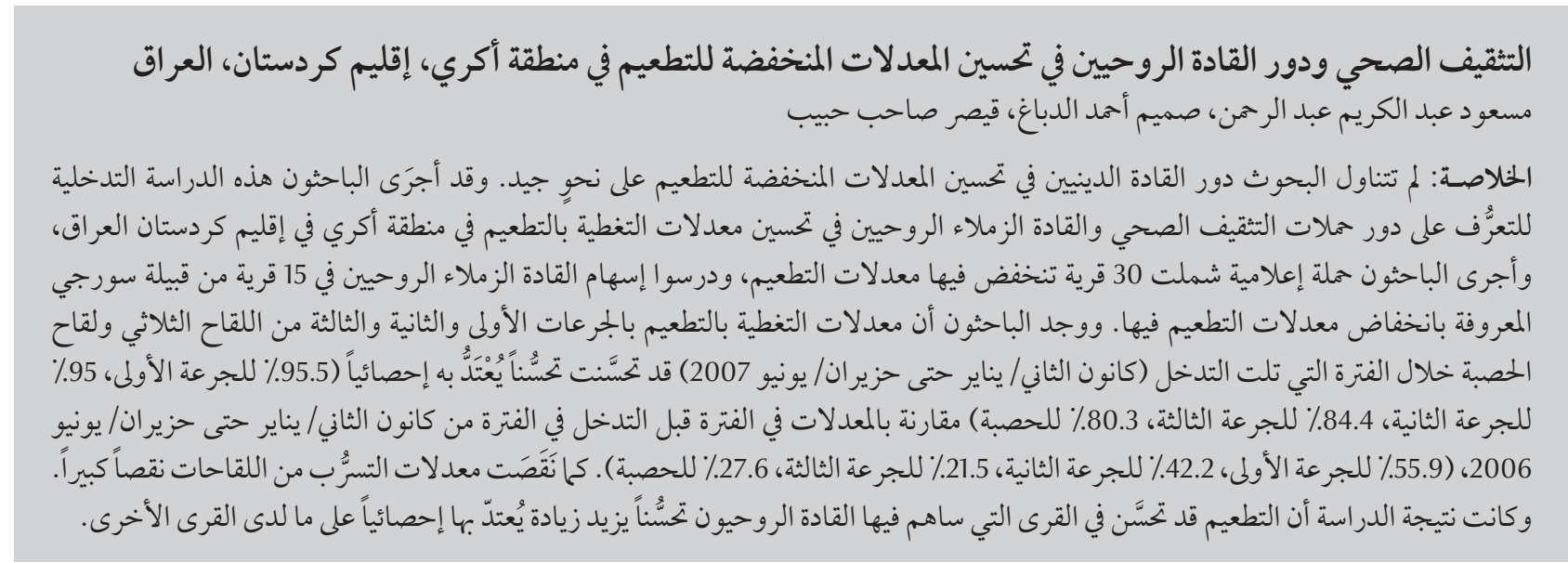

ABSTRACT The role of religious leaders in improving vaccination coverage has not been well researched. This intervention study investigated the role of a health education campaign and peer spiritual leaders in improving vaccination coverage rates in Akre district in Kurdistan region, Iraq. An information campaign was conducted in 30 villages with low vaccination coverage. The participation of peer spiritual leaders was sought in 15 villages of the Sorchi tribe known to have persistent low coverage rates. The vaccination coverage rates of DPT1, DPT2, DPT3 and measles vaccines during the post-intervention period (January to June 2007) were significantly improved (95.5\%, $90.0 \%, 84.4 \%$ and $80.3 \%$ respectively) compared with the pre-intervention period (January to June 2006) (55.9\%, $42.7 \%, 21.5 \%$ and $27.6 \%$ respectively). The dropout rates of those vaccines were also significantly decreased. Vaccination in villages where spiritual leaders were involved improved significantly more than other villages.

Éducation sanitaire et rôle des chefs de groupe dans l'amélioration de la faible couverture vaccinale dans le district d'Akre, région du Kurdistan (Iraq)

RÉSUMÉ Le rôle des chefs religieux dans l'amélioration de la couverture vaccinale n'a pas été bien étudié. La présente étude d'intervention a évalué le rôle d'une campagne d'éducation sanitaire et des chefs de groupe spirituels dans l'amélioration des taux de couverture vaccinale dans le district d'Akre, région du Kurdistan (Iraq). Une campagne d'information a été menée dans 30 villages où la couverture vaccinale était faible. La participation des chefs de groupe spirituels a été recherchée dans 15 villages de la tribu Sorchi, connue pour avoir en permanence des taux de couverture faibles. Les taux de couverture vaccinale pour les première, deuxième et troisième doses du vaccin antidiphtérique-anticoquelucheux-antitétanique et pour le vaccin contre la rougeole pendant la période suivant l'intervention (de janvier à juin 2007) ont nettement augmenté (95,5 \%, 90,0 \%,84,4 $\%$ et $80,3 \%$ respectivement) par rapport à la période précédant l'intervention, de janvier à juin 2006 (55,9\%, 42,7 $\%, 215 \%$ et 27,6 \% respectivement). Les taux des perdus de vue pour ces vaccins ont aussi beaucoup diminué. La vaccination dans les villages où les chefs spirituels étaient impliqués a davantage augmenté que dans les autres villages.

'Department of Family and Community Medicine, Duhok College of Medicine, University of Duhok, Duhok, Iraq (Correspondence to S.A. AlDabbagh:samimaldabbagh@yahoo.com).

Received: 29/08/11; accepted: 05/02/12 


\section{Introduction}

Vaccination is considered to be among the most cost-effective public health interventions programmes [1]. Yet the global commitment to vaccination has not been sustained in all developing countries. In some countries, less than 1 in 3 children are immunized during their first year of life [2].

In Iraq immunization coverage rates in 2005 were less than that of neighbouring countries. In the Kurdistan region the rates of fully immunized infants with valid doses before their 1st birthday were 54\% in Suleimany and 34\% in Erbil and Duhok. The dropout rates between Bacille Calmette-Guérin (BCG) and measles vaccinations were $30.5 \%, 25.0 \%$ and $20.6 \%$ in Erbil, Duhok and in Suleimany respectively. Moreover, annual vaccination statistics of Duhok in 2005 revealed coverage rates for full immunization with oral polio vaccine (third dose), diphtheriapertussis-tetanus (DPT) (third dose) and measles of $64.8 \%, 66.1 \%$ and $60.5 \%$ in the governorate in comparison with $40.3 \%, 40.1 \%$ and $44.3 \%$ in Akre district, which represented the lowest coverage rates among all districts in Duhok [3]. DPT3 coverage rates are the most frequently used to monitor vaccination coverage, while dropout rates are used as indicators of a health system's ability to deliver services requiring multiple visits [4]. The Global Alliance for Vaccines and Immunization set the objective of reaching $90 \%$ coverage at national level and $80 \%$ in each district in all countries by $2010[2,5]$.

In Duhok governorate about $50 \%$ of the causes of vaccination failure or low coverage rates were due to lack of information and motivation $[6,7]$. Studies done in different parts of the world have shown the important role of health education in improving vaccination coverage rates [8]. Education interventions can help people to identify their risk status, indications for specific vaccines and the potential benefits of vaccination and can also reduce or remove barriers by changing negative attitudes and beliefs about vaccination. Yet other studies have provided insufficient evidence to determine the effectiveness of client education in increasing targeted vaccination coverage in adult populations at risk [9-12].

In many developing countries, religious leaders have a legitimacy that political leaders may not have in advocating for vaccination, but their role in improving vaccination coverage has not been fully documented. The aim of this work was to study the effect of health education and the role of peer spiritual leaders in improving low vaccination coverage in Akre district of Duhok governorate in Iraq.

\section{Methods}

\section{Study setting}

This intervention study was carried out in Akre district, which is one of the 6 districts of Duhok governorate, covering $1800 \mathrm{~km}^{2}$ about $120 \mathrm{~km}$ south-east of Dohuk city. Duhok governorate is one of the 3 governorates of Iraqi Kurdistan region. Akre district has 5 subdistricts (Bardarash, Girdasin, Dinarta, Bejiland and central Akre) with a total of 179204 inhabitants (46942 urban and 132262 rural) belonging to 4 main tribes (Goran, Zebaar, Herky and Sorchi).

\section{Study sample}

The strategy for delivery of routine immunization via the expanded programme on immunization (EPI) in Akre district is though 11 fixed units in 11 PHCs in the district, delivering vaccines $1-3$ times per week according to their targets, in addition to 6 mobile outreach teams, which visit villages bimonthly according to a prepared timetable. Based on DPT3 coverage rates during 2005, 260 villages did not achieve the target coverage rate of $80 \%$ with 139 of them having a rate of $<20 \%$.
The sample for the study was achieved by selecting all the target population of selected villages. The villages selected for inclusion in this study had to fulfil a DPT 3 coverage rate < $20 \%$ and a target population (aged $<1$ year) between 15-24 infants. The latter was adopted in order to have a reasonable size of target population for the intervention. The procedure resulted in 30 villages scattered through all subdistricts, 15 of which belonged to the Sorchi tribe.

\section{Intervention}

Before starting the study, a visit was carried out to the family of the local sheikh who was the most influential spiritual leader for the Sorchi population, to request their help in improving vaccination coverage among their tribe, stressing the need for preventing the re-emergence of vaccine preventable diseases such as the pertussis epidemic which occurred in most Sorchi villages during 2005-06. The sheikh's family promised support and offered help by sending, in advance, a verbal message to their recognized representatives in all tribal villages. The message was that the vaccination programme is of great benefit for people in preventing many diseases and that they were requesting all families of the tribe to vaccinate their male and female children, as they did with their family and relative's children. They also gave the research team permission to use that verbal message.

For the health education stage each of the 30 selected villages was offered a visit. Two days before each scheduled visit, the research team met members of the relevant local health unit or with the peer leader in villages where no such units were available. During each visit the planned health education programme was applied by one of the researchers (M.A.) with 2 paramedics from the vaccination unit. Invitation for attendance was done through using loudspeakers, sending children to nearby houses and interpersonal 
communication. The activities lasted for 3 hours and included health talks (lectures), posters and a video film with the participation of local peer leaders. The sessions were held at selected places traditionally known to the villagers as collection sites during special occasions. Recognized representatives of the local sheikh's family were involved with the team in all 15 Sorchi villages.

The post-intervention stage lasted 6 months from January to June 2007. All the procedures conducted, other than health education, were exactly the same as in 2006, i.e. the routine vaccination programme usually conducted by the local Department of Health. The researchers kept a neutral attitude during the post-intervention stage by neither intruding upon the usual vaccination programme of the Directorate of Health nor advocating for an additional vaccination campaign. The main role of the research team was to coordinate the campaign in all aspects and maintain liaison with the sheikh's family representatives in the 15 Sorchi villages.

\section{Data collection and analysis}

Data regarding the numbers of $<1$ year old infants vaccinated with DPT 1, DPT2, DPT3 and measles were collected. The coverage and dropout rates for each village and sub-district were calculated in the same way as during the pre-intervention stage.

Z-test for 2 proportions was employed to detect significant differences between different indicators. A P-value $<0.05$ was considered as statistically significant and $<0.01$ as highly significant.

\section{Results}

Table 1 shows the distribution of the study population during 2006 and 2007. For 2007, the study population was 578 infants for the whole year and as the duration of post-intervention period was 6 months, the denominator of 289 represented half of the annual target.

\begin{tabular}{|c|c|c|c|c|c|}
\hline \multirow[t]{4}{*}{ Sub-district } & \multirow{4}{*}{$\begin{array}{l}\text { No. of } \\
\text { villages }\end{array}$} & \multicolumn{4}{|c|}{ Estimated target population } \\
\hline & & \multirow{2}{*}{\multicolumn{2}{|c|}{$\begin{array}{c}2006 \\
\text { Age (months) }\end{array}$}} & \multirow{2}{*}{\multicolumn{2}{|c|}{$\begin{array}{c}2007 \\
\text { Age (months) }\end{array}$}} \\
\hline & & & & & \\
\hline & & 6 & 12 & 6 & 12 \\
\hline Bardarash & 12 & 119 & 238 & 123 & 246 \\
\hline Girdasin & 11 & 101 & 202 & 105 & 210 \\
\hline Bejil & 4 & 34 & 68 & 35 & 70 \\
\hline Akre centre & 2 & 14 & 28 & 14 & 28 \\
\hline Dinarta & 1 & 11 & 22 & 12 & 24 \\
\hline Total & 30 & 279 & 558 & 289 & 578 \\
\hline
\end{tabular}

Based on Directorate of Duhok Statistics, 2005.

\section{Comparison of pre- and post- intervention vaccination}

The DPT1, DPT2, DPT3 and measles vaccination coverage rates during 2007 in the 30 studied villages were highly significantly improved (95.5\%, 90.0\%, $84.4 \%$ and $80.3 \%$ respectively) compared with those of 2006 (55.9\%, $42.7 \%$, $21.5 \%$ and $27.6 \%$ respectively) $(P<$ $0.001)$. During 2007 the highest coverage rate was that of DPT 1 followed by DPT2 and DPT3 (Table 2).

The dropout rates between DPT1 and DPT3 and between DPT 1 and measles vaccinations both decreased highly significantly from $60.7 \%$ and $49.6 \%$ respectively in 2006 to $11.5 \%$ and $15.9 \%$ respectively during $(P<0.001)$ (Table 3).

\section{Comparison of Sorchi and non-Sorchi tribes}

Generally, vaccination coverage rates during 2007 were higher in the 15 Sorchi tribe villages compared with the 15 non-Sorchi villages. The greatest difference was that of the measles vaccination coverage rate $(P<0.001)$, followed by that of DPT 2 and DPT 3 coverage rates $(P<0.05)$, while the difference related to DPT 1 coverage was not significant $(P=0.148)$ (Table 4).

The DPT 1-measles vaccination dropout rate in the Sorchi tribe villages during 2007 was much lower (8.0\%) than that of non-Sorchi villages
(24.7\%). This difference was highly significant $(P<0.001)$. The DPT1-DPT3 dropout rate in Sorchi villages was also significant decreased (8.0\%) compared with non-Sorchi villages $(15.1 \%)(P<$ 0.05) (Table 5).

\section{Discussion}

In Kurdistan region, significant efforts have been focused on the vaccination programme since 1992. The target of the local Department of Health is that the coverage rate should exceed at least $80 \%$ of the target population. Villages in Akre district, particularly those of the Sorchi tribe, have been shown to have low vaccination coverage and high dropout rates, which were a stimulus to efforts to improve such unaccepted rates [3]. Several studies have shown that health education and motivation can lead to significant improvement in vaccination coverage [8]. There is little or no evidence of such trials being conducted in Kurdistan region and or even in Iraq.

It was decided to study villages with low vaccination coverage rates of $<20 \%$ in order to detect any benefit from the programme and to provide the best assistance to these villages. Moreover these villages constituted $>50 \%$ of all villages with $<80 \%$ coverage rate. Villages with a small target population ( $<14)$ were excluded because it was 


\begin{tabular}{|c|c|c|c|c|c|}
\hline \multirow[t]{3}{*}{ Vaccine } & \multicolumn{4}{|c|}{ Coverage rate } & \multirow{3}{*}{$P$-value } \\
\hline & \multicolumn{2}{|c|}{2006} & \multicolumn{2}{|c|}{2007} & \\
\hline & $\begin{array}{l}\text { No. of infants } \\
\text { vaccinated }\end{array}$ & $\%$ & $\begin{array}{l}\text { No. of infants } \\
\text { vaccinated }\end{array}$ & $\%$ & \\
\hline DPT1 & 156 & 55.9 & 276 & 95.5 & $<0.001$ \\
\hline DPT2 & 119 & 42.7 & 260 & 90.0 & $<0.001$ \\
\hline DPT3 & 60 & 21.5 & 244 & 84.4 & $<0.001$ \\
\hline Measles & 77 & 27.6 & 232 & 80.3 & $<0.001$ \\
\hline
\end{tabular}

\begin{tabular}{|c|c|c|c|c|c|c|c|}
\hline \multirow[t]{3}{*}{ Vaccine schedule } & \multicolumn{3}{|c|}{2006} & \multicolumn{3}{|c|}{2007} & \multirow[t]{2}{*}{$P$-value } \\
\hline & $\begin{array}{c}\text { Infants } \\
\text { vaccinated } \\
\text { with DPTI }\end{array}$ & $\begin{array}{c}\text { Infants } \\
\text { vaccinated } \\
\text { with DPT3 }\end{array}$ & $\begin{array}{l}\text { Dropout } \\
\text { rate }\end{array}$ & $\begin{array}{c}\text { Infants } \\
\text { vaccinated } \\
\text { with DPTI }\end{array}$ & $\begin{array}{c}\text { Infants } \\
\text { vaccinated } \\
\text { with measles }\end{array}$ & $\begin{array}{l}\text { Dropout } \\
\text { rate }\end{array}$ & \\
\hline & No. & No. & $\%$ & No. & No. & $\%$ & \\
\hline DPT1-DPT3 & 156 & 60 & 60.7 & 276 & 244 & 11.5 & $<0.001$ \\
\hline DPT1-measles & 156 & 77 & 49.6 & 276 & 232 & 15.9 & $<0.001$ \\
\hline
\end{tabular}

thought that the effects of such programme might be of limited value if very small numbers of mothers were available. Big villages were also excluded, as it would have been more difficult to implement health sessions and extra time would have been needed to collect participants.

In this study the DPT1, DPT2, DPT3 and measles vaccination coverage rates significantly improved in the intervention villages in 2007, the year of the education campaign, compared with 2006, the year before the intervention. In addition, dropout rates for both DPT1-DPT3 and DPT1-measles vaccinations decreased significantly after the implementation of the health education programme. In an attempt to reduce other possible confounding factors, the post-intervention vaccination programme followed the same pattern as the pre-intervention period as it was conducted for the same duration and the same routine procedures were conducted, except for the implementation of health education. It seems likely therefore that the improvements were related to the educational activities, especially as $50 \%$ of causes of vaccination failure or low coverage rates are believed to be due to lack of information and motivation [7]. Similar results have been reported in other countries $[9,13-15]$.
The study also showed a significantly greater improvement in vaccination coverage post-intervention in villages belonging to the Sorchi tribe in comparison with other villages. By comparing villages with and without a spiritual leader advocating for vaccination we were able to demonstrate a possible association between the intervention of peer leaders and improvement in vaccination coverage rates. These results are consistent with a study conducted in Madagascar in 2003, in which community leaders (local political, administrative and religious leaders) played a role in increasing vaccination coverage above the national average (DPT3 from

\begin{tabular}{|c|c|c|c|c|c|}
\hline \multirow[t]{3}{*}{ Vaccine } & \multicolumn{4}{|c|}{ Coverage rate } & \multirow[t]{3}{*}{$P$-value } \\
\hline & \multicolumn{2}{|c|}{ Non-Sorchi villages } & \multicolumn{2}{|c|}{ Sorchi villages } & \\
\hline & $\begin{array}{l}\text { No. of infants } \\
\text { vaccinated }\end{array}$ & $\%$ & $\begin{array}{l}\text { No. of infants } \\
\text { vaccinated }\end{array}$ & $\%$ & \\
\hline DPT1 & 139 & 94.0 & 137 & 96.5 & 0.148 \\
\hline DPT2 & 127 & 85.8 & 123 & 94.3 & 0.013 \\
\hline DPT3 & 118 & 79.7 & 126 & 89.3 & 0.018 \\
\hline Measles & 106 & 71.6 & 126 & 89.3 & $<0.001$ \\
\hline
\end{tabular}




\begin{tabular}{|c|c|c|c|c|c|c|c|}
\hline \multirow[t]{3}{*}{ Vaccine schedule } & \multicolumn{3}{|c|}{ Non-Sorchi villages } & \multicolumn{3}{|c|}{ Sorchi villages } & \multirow[t]{2}{*}{$P$-value } \\
\hline & $\begin{array}{c}\text { Infants } \\
\text { vaccinated } \\
\text { with DPT1 }\end{array}$ & $\begin{array}{c}\text { Infants } \\
\text { vaccinated } \\
\text { with DPT3 }\end{array}$ & Dropout rate & $\begin{array}{c}\text { Infants } \\
\text { vaccinated } \\
\text { with DPT1 }\end{array}$ & $\begin{array}{c}\text { Infants } \\
\text { vaccinated } \\
\text { with } \\
\text { measles }\end{array}$ & Dropout rate & \\
\hline & No. & No. & $\%$ & No. & No. & $\%$ & \\
\hline DPT1-DPT3 & 139 & 118 & 15.1 & 137 & 126 & 8.0 & $<0.05$ \\
\hline DPT1-measles & 139 & 106 & 24.7 & 137 & 126 & 8.0 & $<0.001$ \\
\hline
\end{tabular}

$50 \%$ in 2002 to $95 \%$ in 2003) and in dropout reduction (below the national average of $12 \%$ ) in 2 provinces [16]. It is well known that interpersonal communication activities with influential local leaders (religious, medical and political) can positively affect a community's trust and willingness to vaccinate their children [10-12,17-20]. The Sorchi tribe is one of the largest tribes in the area, inhabiting more than 120 villages in Akre district. During 2005, the DPT3 coverage rate among them was less than $10 \%$, representing the lowest rate among other tribes in the district. Sorchi populations bear great respect, loyalty and obedience to the local sheikh's family, regarding them as the reference spiritual and religious authority. It has been noted that when avian influenza was reported the sheikh's family requested their neighbours to remove their domestic birds and next day all such birds were slaughtered by all tribe fellows.

Comprehensive health education especially modulated to suit the different educational levels with active involvement of local tribes and spiritual leaders is recommended in plans to improve vaccination coverage rates.

\section{References}

1. Canada Communicable Diseases Report: measuring up results from the national immunization coverage survey in 2002. Ottawa, Ontario, Public Health Agency of Canada, 2004.

2. State of the world's vaccines and immunization. Geneva, World Health Organization, 2002.

3. Annual review of Duhok DOH: activities in 2005. Duhok, Iraq, Directorate of Health Dohuk, 2006.

4. Bos E, Batson A. Using immunization coverage rates formonitoring health sector performance. Measurements and interpretation issues. HNP Discussion Paper. Washington DC, World Bank, 2000.

5. Immunize every child: GAVI strategy for sustainable immunization services. New York, Global Alliance for Vaccines and Immunization, 2000.

6. Ministry of Health, Kurdistan Region/UNICEF Iraq. Household immunization coverage survey, 2007. Duhok, Iraq, Hawar Press, 2007.

7. Immunization summary: the 2007 edition. A statistical reference containing data through 2005. New York, United Nations Children's Fund, 2007.

8. Shefer A et al. Improving immunization coverage rates: an evidence-based review of the literature. Epidemiologic Reviews, 1999, 21:96-142.

9. Porter RW et al. Role of health communications in Russia's diphtheria immunization program. Journal of Infectious Diseases, 2000, 181(Suppl. 1):S220-S227.

10. Das J, Das S. Trust, learning, and vaccination: a case study of a North Indian village. Social Science and Medicine, 2003, 57:97-112.

11. Verma AK, Bansal RK, Pawar AB. Facilitating behavioral change for acceptance of oral polio vaccine. Indian Pediatrics, 2004, 41:951-952.
12. Ndiaye SM et al. Interventions to improve influenza, pneumococcal polysaccharide, and hepatitis $B$ vaccination coverage among high-risk adults: a systematic review. American Journal of Preventive Medicine, 2005, 28(Suppl.):248-279.

13. Zimicki $S$ et al. Improving vaccination coverage in urban areas through a health communication campaign: the 1990 Philippine experience. Bulletin of the World Health Organization, 1994, 72:409-422.

14. Jassim AK et al. Visceral leishmaniasis control in ThiQar Governorate, Iraq. Eastern Mediterranean Health Journal, 2003, 12:933-940.

15. Anjum $Q$ et al. Improving vaccination status of children under five through health education. Journal of the Pakistan Medical Association, 2004, 54:610-613.

16. Shimp L. Strengthening immunization programs: the communication component. Arlington, Virginia, Basic Support for Institutionalizing Child Survival Project (BASICS II) for the United States Agency for International Development, 2004.

17. Building trust in immunization: partnering with religious leaders and groups. New York, United Nation Children's Fund, 2004.

18. Ilika AL, Emelumadu OF, Okonkwo IP. Religious leaders' perceptions and support of reproductive health of young people in Anambra State, Nigeria. Nigerian Postgraduate Medical Journal, 2006, 13:111-116.

19. Obregón $\mathrm{R}$ et al. Achieving polio eradication: a review of health communication evidence and lessons learned in India and Pakistan. Bulletin of the World Health Organization, 2009, 87:624-630.

20. Somali religious leaders join the fight against polio. Press release, 18 July 2007. UNICEF [online] (http://www.unicef.org/media/ media_40360.html, accessed 11 November 2012). 